\title{
Study on Aesthetics of the New Style of Chinese Tea Ware Culture
}

\author{
Chunyan $\mathrm{Wu}$ \\ Students' Development and Transaction Centre \\ Jinzhou, China
}

\begin{abstract}
The rise of the new style of Chinese tea ware is the rise of the Chinese national spirit. The new Chinese style tea ware combines elements of modern and traditional cultural, with a national way to show the historical inheritance and accumulation of Chinese traditional culture. The new style of Chinese tea ware has culture aesthetic features, with the characteristic of stable and harmonious, generation among five elements, recover the original simplicity, national elements and some other culture aesthetic feature elements.
\end{abstract} study

Keywords—new Chinese style; tea ware; culture aesthetic;

\section{INTRODUCTION}

China is the hometown of tea, and is also the first country in the world to grow and use tea. Tea has accompanied the ancient Chinese nation for a long time. In the contemporary era tea is not only a national drink of the Chinese nation, but also a profound Chinese culture. Chinese tea culture is the unique cultural characteristics, formed in the process of tea picking, tea making, tea drinking and tea appreciating, and with rich contents, including tea science, tea ceremony, tea art, tea book, tea ware, tea painting, tea story and other aspects. With the development of economic society, tea drinking is not only to satisfy the original intention of thirst quenching, but also to pursue the pleasure of spiritual life and to adjust the demand of joyful body and mind. While drinking tea, you may feel first bitter then sweet, from warm to cool, although it is just a process, tastes are thousand kinds, that is fragrance of life. More and more people are using the aesthetic aspect to pursuit the beauty of tea ware, especially with the fashion of new Chinese style, tea ware begin to show the beauty of it.

\section{INTERPRETATION OF NEW CHINESE STYLE}

The new Chinese style is relative to the Chinese style, Chinese style also called Chinese traditional palace style, with the features of magnificent and elegant, splendid and sumptuous, shape symmetry, color contrast and so on, and the new Chinese style was born in the new period of China traditional cultural renaissance. With the development of our economic society, the national consciousness of Chinese people has gradually become prominent, and new thinking concepts and development ideas have been sought from the original "imitate and copy" western style. At the beginning of the searching local consciousness of Chinese design style,

The Project is supported by Bohai University, Students' Development and Transaction Centre. especially the designers of tea ware, gradually formed and developed the new style of mature, implicit and graceful. The new Chinese style is not the full sense of the ancient Ming and Qing Dynasty, but through the characteristics of Chinese style to express pursue of the elegant implicit, dignified decent mental realm.

The new Chinese style has two basic elements: first is the China traditional style reinterpretation of cultural significance in the context of the current era; second is the contemporary design on the basis of the full understanding of Chinese contemporary culture [1]. The new Chinese style is not a simple copy and a stack of traditional elements of traditional culture, but through the re understanding and reinterpretation, then reflect the cultural spirit and achieve sublimation, combining modern elements and traditional elements in contemporary aesthetic needs to build things full of traditional charm, make the traditional art form and get the right spirit in today's society.

\section{InTERPRETATION OF THE NEW Chinese Style TEA WARE}

In the beginning, people drank tea by using eating utensils. The common characteristics of all kinds of wares in ancient Chinese society are various appliances and multiple uses. When the development of tea drinking to a certain stage, people feel the need for a special device, then specialized tea sets appeared. First Century BC, Sichuan Wangbao said in his book "Tong Yue" :" buy tea in Wuyang" "use ware to make tea" or something like that, indicating that tea making has special utensils, tea wares began to produce [2]. While the "the Sage of Tea" Lu Yu said in " the Classic of Tea", wind furnace, bowls, napkins, columns, baskets and other 24 kinds of tea wares were designed then. Thus, the ancient tea drinking is not only a requirement of physical activity, but also spiritual needs of the arts, in the appliance of material and spiritual activities, wares play an important role. People use tea wares, not only to the pursuit of its useful and helpful, but also pursuit its vivid and lively, proper and logical, aesthetic as well. At present, with the development of economic society, people also gradually improve the aesthetic demand of tea ware, and more and more new Chinese style has integrated into the design and use of tea set and tea ware, showing a strong trend of "new Chinese style".

The new Chinese style tea ware, is based on the unscramble and reconstruction of Chinese traditional cultural meaning, with an artistic concept of different styles of mixed material 
collocation and symmetric contrast, combining modern elements and traditional elements, making the tea ware with modern beauty and classic charm. This is the thousand years China history of the development of tea culture in the accumulation of the spirit in the contemporary art of sublimation and charm, makes the traditional Chinese culture presented suitable material form and artistic spirit embodied in modern society.

The popular of new Chinese tea ware, is the rise of the depressed Chinese national spirit, and is also the self acceptance and enhance to the self-confidence of the Chinese nation. Chinese people are willing to show their historical heritage and national cultural heritage in a national way. 5000 years of China's history breeds the brilliant cultural civilization, but as the Opium War begins, the history of the Chinese people is deeply humiliated, and the Chinese people have a strong sense of inferiority. This psychology has paved the way for the anti tradition later on. The accumulation of the long-term inferiority, when people get independence, it is an urgent to change the status quo of spiritual demand, industrialization and modernization become a counterculture revolution. Until the reform and opening up thirty years later, China, which full of materials, began to re-examine the civilization for thousands of years, only to recall the national culture information, to reflect the charm of elements of traditional culture in the process of industrialization, this is a great enhance to national selfconfidence, and is shining the youth of Chinese traditional culture.

\section{INTERPRETATION OF THE NEW Chinese StYle TeA WARE CULTURE AESTHETIC}

The new Chinese style tea ware has a kind of "simple in its shape, heavy in its connotation" pattern of manifestation on ware shape, and also presents the cultural aesthetic elements on the shape of new Chinese style tea ware. This new Chinese style tea ware culture aesthetics embodied in the following aspects.

\section{A. The Beauty of Harmony and Steady}

The new Chinese style pays attention to the return of the traditional cultural spirit and advocates the spiritual connotation of Chinese traditional culture. Chinese traditional culture attaches importance to the harmonious universe view of "harmony between man and nature", and emphasizes the smooth and steady. Then, the spirit of harmony and steady on traditional culture express in ware are the type of symmetrical and the beauty of symmetrical. In the process of the design and production of new Chinese style tea ware, combine the symmetry and the art form of tea ware, make the tea ware itself with aesthetic performance, but also conform to the people's usage intention, so that tea ware can reach suitable, safe and beautiful goal.

Symmetry refers to a point as the axis, get up and down or left and right symmetrical and balanced presentation of the symmetry and this balance to a certain extent also reflects the philosophy of life and a middle course of traditional culture. From the new Chinese style tea ware, it is not difficult to find: up to now, the beauty of symmetry in Chinese tradition, generally can be realized as the approximate symmetry, exact symmetry and inversion symmetry these three forms. For example, the tea cup we often use, the most basic type is a circular cup, which is the exact symmetry of the threedimensional axis, one of the purple clay teapots there is one called ruyi teapot which is also exact symmetry of the threedimensional axis. The shape feature of the purple clay square teapot is boxy, it is the three-dimensional symmetric of the solid axis. The song pot made by Purple clay craft master Wang Yinxian, flying crank and meaningful spout forms two concentric inversion symmetry beauty in three-dimensional space, her musical euphemistic elegant lines showed Chinese culture's "combine square and round" attitude towards life, also with this kind of harmonious attitude towards life made the Chinese nation still full of vigor after experienced countless disasters. The most distinctive feature of the new Chinese style tea set is the Taiji Yin Yang pot, which fully demonstrates the beauty of the approximate symmetry of the Yin and Yang of Chinese traditional culture.

\section{B. The Beauty of the Generation among Five Elements}

The ancients believed that: everything is consisted of five elements gold, wood, water, fire and earth, and that is the five elements. "Five elements: first is water, second is fire, third is wood, fourth is gold, fifth is soil ("Shangshu hongfan ") [3], China ancient philosophers illustrate the formation of the world and their relationship with the five elements theory, it emphasizes the overall concept and the dao process rule, the aim is to describe the motion forms of object and the relationship between form and transformation. The theory of five elements belong to the Chinese ancient natural philosophy, but in the process of its development, is widely applied to China social system, ideology and culture, aesthetics and art language and other fields, till today, the new Chinese style tea ware also presents the five elements of art aesthetics.

The beauty of five elements not only reflected in the use of gold, wood, water, fire and soil these five elements in the process of design and produce the new Chinese style tea ware, but also the spirit of the five elements shown in the new Chinese style design and production of tea ware. For example, a company push out a series of tea ware, designers choose simple and classical color of walnut as an important part of the white porcelain tea ware, "kettle", "pot", or set of device tray, demonstrate the combination of elements "wood" and "soil", and "wood" represents the East range, but also the return of the oriental culture and oriental civilization. As one of the five famous kilns, $\mathrm{Ru}$ Kiln, though still use clay as the raw material, finished products have natural law beauty through the " generation among five elements". The fusion of fetal soil and glazes on behalf of the fusion of "soil" and "water", the process of high temperature kiln is the aesthetic evolution from "wood" evolved into "fire", finally when people drinking tea, hacking is formed, this is the forming beauty of "golden silk". "The generation of five elements", this art aesthetics was successfully presented in the process of $\mathrm{Ru}$ Kiln's making, firing and using.

\section{The Beauty of Recover Original Simplicity}

The beauty of recover the original simplicity, is the pure state which traditional culture advocates, remove the external decoration, restore the original state. There is a saying in "Strategies of the Warring States, the fourth part of Qi", a 
gentleman says: satisfy when you learn some knowledge, if you don't have the ability to do a great job, just live a normal life, this kind of life can be a success, this is also the pursuit of Chinese Taoism. In Chinese Taoism, the purpose to learn Taoism is to make the life return to the initial state, through their own practice, this is called "recover the original simplicity". Taoism believes that the original nature of man is simple and pure, and is close to the nature of tao. However, "return to nature" needs to hold the park, "Tao Te King" says: "keep the pure nature, have less self desire ". That is to be simple and innocent, maintain the element of life, so as not to be tempted by material desire, not to be worried by selfish ideas, let the life return to the real faith state.

The recover original simplicity beauty of the new Chinese style tea ware embodies in the use of ware type and material. The new Chinese style tea sets often use pristine kind of ware, such as the Qing Dynasty painter, engraver Mr.Chen Hongshou, created the "Mansheng eighteen style" purple clay teapot, which has an aesthetic orientation of literati, integrate the plain, personality of truth, poetry mood, elegant calligraphy, vivid painting into the purple clay teapot, so that the art of teapot reached a consummate realm, made the future generations admire. Today, the modern purple clay teapot craft master $\mathrm{Gu}$ Jingzhou and other predecessors still follow the "Mansheng eighteen style" basic pot type, and carries on the craft improvement and technology perfection.Tea burning crude pottery of the new style of Chinese tea ware has attracted more and more urban white-collar workers and business people's welcome, is a manifestation of the pursuit of "recover the original simplicity" when people under the intense work mood state and mental pressure. At the same time, urbanite have a special liking to the blue and white porcelain, colour enamels, temmoku glaze, stone glaze, rattan plaited articles, bamboo, and wares which pursuit of "simple" style, this fully shows that people's spiritual pursuit of the original life from heart.

The new Chinese style tea ware also selected flower, grass, insect, fish from nature, cultural customs, the simple and unadorned and kind-hearted natural instincts which people pursue as aesthetic elements to decorate tea set and tea ware, landscape modification in a modern way, showing a different mix of style, make tea set with modern sense of aesthetic, and also with traditional charm. Like a company produce a kind of mug, dendrobium, interlock branch lotus, twelve zodiac and plum blossoms, orchid, bamboo, chrysanthemum four elements are used and is popular among people.

\section{The Beauty of National Elements}

National element refers to the Chinese traditional culture spirit which is recognized by Chinese and the image symbols or customs which embodies the national dignity and national interest. The new Chinese style tea ware is the recognition and call again to the traditional Chinese culture, based on the development of our country's economic society, so people pay more attention to the use of ethnic elements in tea ware.

Chinese calligraphy, seal carving, dragon phoenix flower pattern, auspicious clouds gluttonous figure, facial makeup in Peking Opera, cultural relics and historic sites, motherland scenery and the elements which quite rich of ethnic characteristics have all become presentation elements in new
Chinese style tea ware . In November 2014, China hosted the APEC summit, the Chinese banquet tableware and tea set is the typical ethnic characteristics of the flower pattern, the design concept of the full set of porcelain is from " the Book of Songs", " bell sounds beautiful, wish you good luck". Dynamic beauty of the winding vine, exquisite beauty of peony, lily, passion flower and other six kinds of flowers, the rich of colors make people just like going slowly into the garden of Chinese culture, brings together all the good wishes like wealth, lucky and healthy. The hole set of porcelain is exquisite and elegant, the graceful cultural pattern and the fresh creative design all express and transfer the blending and mutual between Chinese culture and world culture, all show Chinese national lingering charm. In 2016, during the G20 Hangzhou summit, various tea sets also presented the design concept of West Lake elements and Jiangnan charm. Among them, the main picture of "national beauty and heavy fragrance" series of blue and white porcelain is the traditional Chinese peony flower shape with modern elements.

\section{CONCLUSION}

The new Chinese style tea ware has obvious aesthetic characteristics of Chinese traditional culture, this is the artistic presentation and value return of the Chinese traditional culture. When the material civilization is highly developed, Chinese people begin to pay more attention to and understand the national culture and the national heritage, and the reunderstanding of this spiritual civilization has also promoted the further development of material civilization in our country. In the journey of building a well-off society in an all-round way, it is necessary for us to bring into full play the great potential advantages of Chinese traditional culture and realize the Chinese dream of the great rejuvenation of the Chinese nation. Grinding tea makes dust fly, milky froth makes tea tasty. Few people know the nonsuch, even the sage of tea didn't find it. (Song - Lin bu "Tea").

\section{REFERENCES}

[1] Wei Chen, "Blossom Age"-Take the modern and retro to the end [J].Quality,2008(05):94-95.

[2] Yao Weijun, "Free talk on Chinese tea sets" [J], Democracy, 1996.(05):31.

[3] Qi Mingshan, "The administrative law of dynasties in China" — brief analysis "Shangshu, Hongfsn" [J], Newspaper of Beijing Administrative College, 2000.(04):5-9. 